\title{
Caracterización molecular de materiales cultivados de gulupa (Passiflora edulis f. edulis)
}

\author{
Natalia Fonseca-Trujillo, María del Pilar Márquez-Cardona*'Jairo Hernán Moreno-Osorio, \\ Wilson Terán-Pérez e Ingrid Schuler-García \\ Unidad de Biotecnología Vegetal, Facultad de Ciencias, Pontificia Universidad Javeriana Cra $7^{\circ}$ No. 43-82, \\ Laboratorio 206. Edificio Jesús Emilio Ramírez. Bogotá, D.C, Colombia. \\ *marquez.maria@javeriana.edu.co
}

Recibido: 20-11-2009; Aceptado: 05-02-2010

\begin{abstract}
Resumen
Objetivo. Caracterizar mediante marcadores moleculares RAM (Random Amplified Microsatellite) la diversidad genética de materiales cultivados de gulupa (Passiflora edulis f. edulis), colectados en los departamentos de Boyacá, Cundinamarca y Huila. Materiales y métodos. Hojas jóvenes y en buen estado fitosanitario fueron colectadas en fincas productoras de gulupa, para la extracción de ADN y caracterización mediante marcadores moleculares RAM, de acuerdo con el protocolo descrito por Hantula (1996). A partir de los perfiles de bandas obtenidos, se generaron datos binarios de presencia (1) y ausencia (0). Los datos fueron analizados con el programa estadístico NTSYS- pc versión 2.0, obteniéndose una matriz de similitud utilizando el coeficiente o índice de Dice. Resultados. Los marcadores RAM fueron eficientes para detectar polimorfismos en esta especie, en total fueron usados cuatro primers universales, con los cuales se obtuvo un polimorfismo de $88,8 \%$. En términos generales con los marcadores RAM se evidenció una amplia diversidad genética distribuida en las zonas en las que se cultiva la gulupa en el país. En el presente estudio no se encontró una concordancia con la procedencia de las muestras por departamento o localidad. Conclusiones. Los materiales de gulupa evaluados en este estudio mostraron una alta diversidad genética $(0,291-1)$, probablemente producto del método de propagación, de su procedencia diversa y el poco tiempo de establecimiento de los cultivos en el país
\end{abstract}

Palabras clave: gulupa, RAM, diversidad genética

\begin{abstract}
Molecular characterization of cultivated materials of gulupa (Passiflora edulis f. edulis). Objective. To evaluate through RAM (Random Amplified Microsatellites) molecular markers the genetic diversity of cultivated materials of gulupa (Passiflora edulis f. edulis), collected in the departments of Boyacá, Cundinamarca and Huila. Materials and methods. Young and healthy leaves were collected from crop fields of gulupa for DNA extraction and characterization through RAM molecular markers, according to Hantula's protocol (1996). Binary data of the type presence/absence were collected from the electrophoretic profiles. Data were analyzed with NTSYS- pc- 2.0 statistical package, obtaining a similarity matrix using the Dice coefficient. Results. RAM markers were efficient in detecting polymorphism in this species. Four universal primers were used that produced $88.8 \%$ of polymorphism. In general terms, with the RAM molecular markers a high genetic diversity was detected in the areas where gulupa is cultivated in Colombia. In the present study no geographical relatedness was found with the accessions evaluated for department or locality. Conclusions. The materials of gulupa evaluated in this study showed a high genetic diversity (0.291-1), probably due to the propagation method, its diverse provenances and the short time of establishment of the culture in Colombia.
\end{abstract}

Key words: gulupa, RAM, genetic diversity 


\section{Resumo}

Caracterização molecular de materiais cultivados de gulupa (Passiflora edulis f. edulis). Objetivo. Caracterizar por marcadores moleculares RAM (Random Amplified Microsatellite) a diversidade genética dos materiais cultivados de gulupa (Passiflora edulis f. edulis), coletados nos departamentos de Boyacá, Cundinamarca e Huila. Materiais e métodos. Folhas jovens e em bom estado fitossanitário foram coletadas em fazendas produtoras de gulupa para extração de ADN e caracterização por marcadores moleculares RAM, de acordo com o protocolo descrito por Hantula (1996). Dos perfis de bandas obtidos foram gerados dados binários de presença (1) e ausência (0). Os dados foram analisados pelo programa estatístico NTSYS-pc versão 2.0, produzindo uma matriz de similaridade usando o coeficiente ou índice de Dice. Resultados. Os marcadores RAM foram eficientes na detecção de polimorfismos nesta espécie, foram utilizados quatro primers universales, com os quais se obteve um polimorfismo de $88,8 \%$. No geral, com os marcadores RAM revelou-se uma ampla diversidade genética distribuída em áreas onde se cultiva a gulupa no país. O presente estudo não encontrou uma correspondência com a origem das amostras por departamento ou localidade. Conclusões. Os materiais de gulupa avaliados neste estudo mostraram alta diversidade genética $(0,291-1)$, provavelmente como resultado do método de propagação, de sua origem diversa e ao pouco tempo de estabelecimento dos cultivos no país

Palavras-chave: gulupa, RAM, diversidade genética

\section{Introducción}

La gulupa Passiflora edulis Sims f. edulis, es una especie neotropical perteneciente a la familia Passifloraceae, es originaria de Brasil y fue introducida a otros países de América del Sur durante el siglo XIX (1). En Colombia la gulupa es cultivada entre los 1800 y $2400 \mathrm{msnm}$ y su fruto es considerado como promisorio, con un alto potencial en el mercado agrícola colombiano y de exportación. Su sabor, apariencia, valor nutricional, disponibilidad, accesibilidad y propiedades medicinales, además de su connotación exótica, la hace un producto de alta demanda en el mercado internacional (2).

Entender la diversidad y estructura genética de especies vegetales con alto potencial, como la gulupa, es de suma importancia, ya que permite la implementación de estrategias efectivas para su conservación y mejoramiento. La existencia de variabilidad entre las especies y poblaciones de la misma especie, conlleva a un beneficio a la hora de implementar programas de mejoramiento y selección de materiales con interés agrícola y ecológico.

En Colombia, los estudios realizados para analizar el nivel de diversidad presente en el género Passiflora son escasos, especialmente en Passiflora edulis f. edulis. Por lo tanto, existe la necesidad de llevar a cabo estudios de diversidad genética con el fin de desarrollar estrategias para la conservación y mejoramiento, con el fin de optimizar el uso y productividad de estos materiales vegetales.

La caracterización a través marcadores moleculares es una valiosa herramienta que tiene varias ventajas, como su independencia del medio ambiente y el alto nivel de polimorfismo que se puede encontrar distribuido por el genoma; la técnica RAM (Microsatélites Amplificados al Azar) com- bina características del análisis de las técnicas RAPD y microsatélites (3) presentando características deseables en el análisis, como son su buena reproducibilidad, su sencillez, el bajo costo y que no se necesita información previa del genoma del organismo (4). Con este estudio se caracterizaron molecularmente materiales cultivados de Passiflora edulis f. edulis pertenecientes a áreas productoras de los departamentos de Boyacá, Cundinamarca y Huila.

\section{Materiales y métodos}

El proyecto se desarrolló en dos fases, una fase de campo y una de laboratorio. La fase de campo se llevó a cabo en zonas productoras de gulupa, en los departamentos de Boyacá, Cundinamarca y Huila.

La fase de laboratorio se realizó en el Laboratorio de Biología Molecular de la Unidad de Biotecnología Vegetal de la Pontificia Universidad Javeriana.

\section{Fase de campo}

Se muestrearon tres de los departamentos con mayor producción de la fruta en Colombia (Boyacá, Cundinamarca y Huila), en total se muestrearon 6 municipios, 15 veredas y 16 fincas con producción de gulupa.

En cada vereda se visitaron fincas productoras en donde, de manera aleatoria se seleccionaron plantas de las cuales se colectaron hojas en buen estado (jóvenes y en buenas condiciones fitosanitarias). Las hojas colectadas se pusieron en bolsas sellables con sílica gel y fueron mantenidas a baja temperatura. Una vez en el laboratorio, se 
mantuvieron a una temperatura de $-70^{\circ} \mathrm{C}$, para posteriormente realizar la extracción de ADN y el análisis molecular. En total fueron colectadas 27 muestras de plantas diferentes (Tabla 1).

Tabla 1. Muestras de Gulupa analizadas, Municipio- Departamento

\begin{tabular}{cc}
\hline Individuo & Procedencia \\
\hline 39 & La Plata, Huila \\
55 & Gigante, Huila \\
62 & Palestina, Huila \\
66 & Palestina, Huila \\
69 & Palestina, Huila \\
74 & Palestina, Huila \\
75 & Palestina, Huila \\
80 & Pitalito, Huila \\
92 & Palestina, Huila \\
93 & Gigante, Huila \\
94 & Venecia, Cundinamarca \\
95 & Venecia, Cundinamarca \\
96 & Venecia, Cundinamarca \\
97 & Venecia, Cundinamarca \\
100 & Venecia, Cundinamarca \\
101 & Venecia, Cundinamarca \\
102 & Venecia, Cundinamarca \\
103 & Venecia, Cundinamarca \\
107 & Buena Vista, Boyacá \\
108 & Buena Vista, Boyacá \\
109 & Buena Vista, Boyacá \\
110 & Buena Vista, Boyacá \\
111 & Buena Vista, Boyacá \\
112 & Buena Vista, Boyacá \\
114 & Buena Vista, Boyacá \\
118 & Buena Vista, Boyacá \\
119 & \\
&
\end{tabular}

\section{Fase de laboratorio}

Extracción de ADN. Las hojas colectadas fueron maceradas con nitrógeno líquido hasta obtener un polvo fino. La extracción de ADN fue realizada siguiendo el protocolo de McCouch (1988) (5) estandarizado por Solano et al. (2009), (6).

El ADN aislado de cada una de las muestras fue corrido en geles de agarosa al $0,8 \%(\mathrm{p} / \mathrm{v})$, teñidos con bromuro de etidio (BrE) $(5 \mu \mathrm{g} / \mathrm{ml})$ y visualizados en un transiluminador de luz UV para comprobar la calidad del ADN extraído. La concentración del ADN fue estimada por espectrofotometría con el espectrofotómetro NanoDrop ${ }^{\mathrm{TM}} 1000$.
Análisis con Marcadores RAM. Las reacciones con marcadores RAM fueron realizadas de acuerdo con el protocolo descrito por Hantula (1996) en un volumen final de $25 \mu \mathrm{l}$ (Buffer PCR 1X, $\mathrm{MgCl}_{2} 2.5 \mathrm{mM}$, dNTPs $0.25 \mathrm{mM}$, Taq polimerasa $1 \mathrm{U}$, primer $7 \mu \mathrm{M}$, ADN $25 \mathrm{ng}$ ). Las amplificaciones fueron realizadas en un termociclador (MJ Research, Inc.) usando el siguiente programa: denaturación inicial de $95^{\circ} \mathrm{C}$ por 10 minutos, seguido por 37 ciclos de: denaturación a $95^{\circ} \mathrm{C}$ por 30 segundos; la temperatura de hibridación varió de acuerdo al primer utilizado así: $54^{\circ} \mathrm{C}$ (Primer AG), $44^{\circ} \mathrm{C}$ (Primer CGA y CGA), $50^{\circ} \mathrm{C}$ (Primer $\mathrm{CT}), 58^{\circ} \mathrm{C}$ (Primer TG y GT), $41^{\circ} \mathrm{C}$ (Primer CA, y $45^{\circ} \mathrm{C}$ (Primer GACA) durante 45 segundos; extensión a $72^{\circ} \mathrm{C}$ por 2 minutos y una extensión final a $72^{\circ} \mathrm{C}$ durante $7 \mathrm{mi}$ nutos.

Los productos de amplificación fueron analizados por electroforesis en geles de agarosa al 1,5\% (p/v), teñidos con bromuro de etidio y corridos por dos horas y media a un voltaje constante de $90 \mathrm{~V}$. Los geles fueron visualizados en un transiluminador de luz UV, fotografiados y almacenados en archivos digitales.

En total fueron probados siete primers de RAM descritos por Hantula (1996), de los cuales se usaron cuatro para el análisis de las muestras de ADN de gulupa. Con el fin de confirmar la reproducibilidad de los marcadores RAM, se realizaron dos repeticiones de las PCR con cada uno de los primers evaluados. Solo las bandas que amplificaron consistentemente fueron incluidas en el análisis.

Análisis estadístico. A partir de los perfiles de bandas obtenidos, se generaron datos binarios de presencia (1) y ausencia (0), que se registraron en una matriz de Excel. A partir de la matriz binaria se construyó con el programa estadístico Numerical Taxonomy System for Personal Computer NTSYS- pc versión 2.0, (2), una matriz de similitud utilizando el coeficiente o índice de Dice. Una vez obtenida la matriz de similitud se agruparon los datos en clusters en un dendrograma, el análisis de agrupamiento se realizó con la herramienta SAHN, utilizando el algoritmo UPGMA, el cual permitió visualizar en dos dimensiones las similitudes o diferencias entre los materiales evaluados. El dendrograma se construyó con la herramienta TREE de NTSYS - pc versión 2.0, (2).

\section{Resultados}

Los marcadores RAM fueron eficientes para detectar polimorfismos en esta especie. De los siete primers ensayados, fueron elegidos cuatro por su polimorfismo y reproducibilidad de las bandas amplificadas, estos primers dieron un 
total de 45 bandas, de las cuales 40 fueron polimórficas, lo cual representa un $88.8 \%$ de polimorfismo (Tabla 2).

Tabla 2. Primers polimórficos elegidos para realizar el análisis de Passiflora edulis f. edulis y porcentaje de polimorfismo detectado por medio de los RAM

\begin{tabular}{cccc}
\hline Primer & $\begin{array}{c}\text { Número } \\
\text { de } \\
\text { Bandas }\end{array}$ & $\begin{array}{c}\text { Número de } \\
\text { Bandas } \\
\text { Monomórficas }\end{array}$ & $\begin{array}{c}\text { Número de } \\
\text { Bandas } \\
\text { Polimórficas }\end{array}$ \\
\hline CT & 13 & 2 & 11 \\
CA & 7 & 3 & 4 \\
GT & 15 & 0 & 15 \\
CGA & 10 & 0 & 10 \\
Total & 45 & 5 & 40 \\
\hline
\end{tabular}

$\%$ Polimorfismo $=88,8 \%$

El alto número de marcadores por primer y el alto porcentaje de marcadores polimórficos dentro de la especie $P$. edulis f. edulis evidencian la presencia de una alta variabilidad intraespecífica con los marcadores evaluados (Tabla 2).
La figura 1 muestra la agrupación de los 27 genotipos de gulupa analizados, las similitudes de los genotipos analizados se encuentran entre 0,26 y 1,0 . Al realizar un corte en el dendrograma en 0,34 es posible diferenciar dos genotipos que se separan claramente de los demás. El primer genotipo en separarse es el 114 (Buenavista - Cundinamarca) a un coeficiente de 0,26 . El segundo genotipo en separarse es el 39 (La Plata - Huila) a un coeficiente de 0,30. Los demás genotipos se empiezan a separar a un coeficiente de 0,38 , formando diferentes subgrupos.

Los genotipos 95 y 96, ambos provenientes del municipio de Venecia (Cundinamarca) son exactamente iguales, según los resultados arrojados por estos marcadores moleculares. Igualmente los genotipos 74, 92, 109, 110 y 111 provenientes de los municipios de Palestina (Huila) y Buena Vista (Boyacá) tienen una similitud del 100\%, según los resultados arrojados por los marcadores RAM.

\section{Discusión}

\section{Análisis de diversidad}

Este estudio es un primer acercamiento al conocimiento de la diversidad genética de genotipos cultivados de gulupa en Colombia y demostró que la técnica RAM empleada es

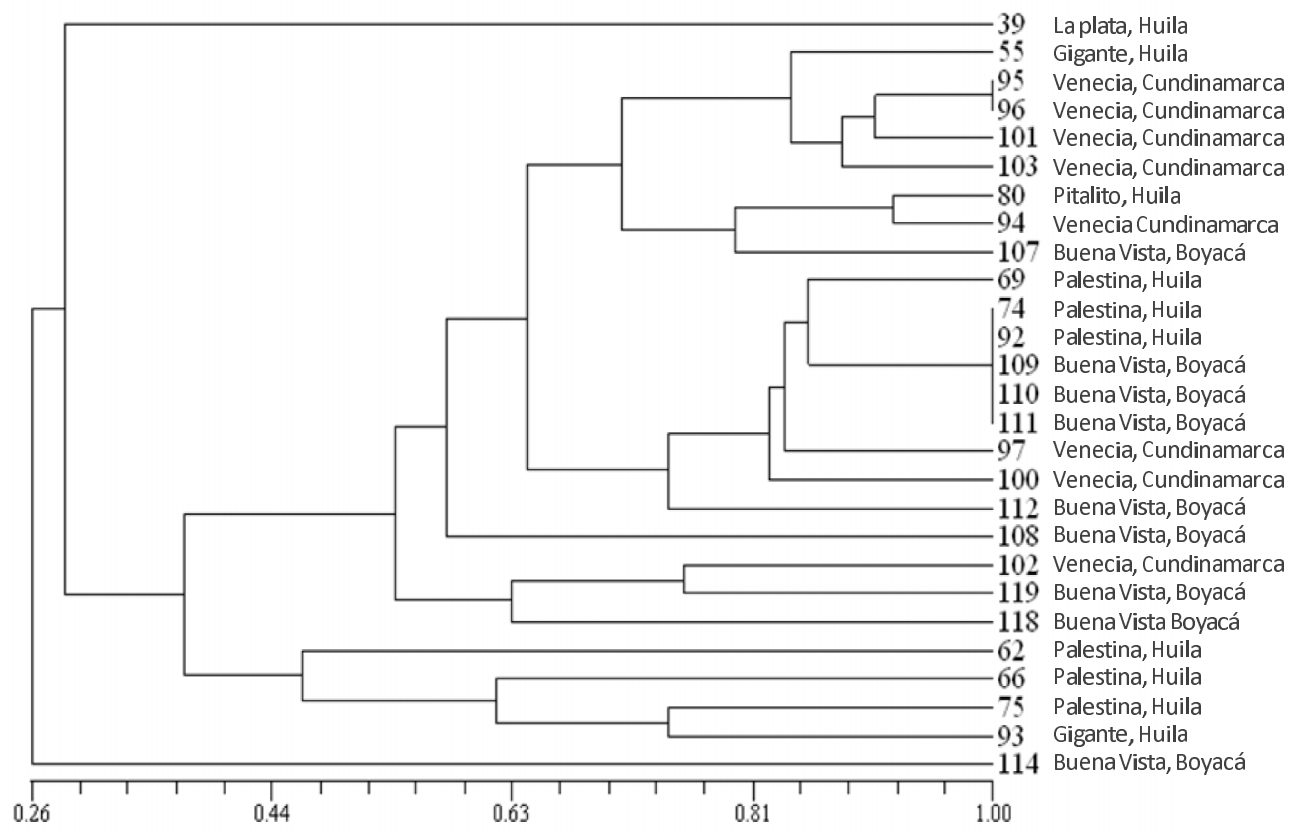

Figura 1. Análisis de agrupamiento con el algoritmo UPGMA de 27 genotipos de Passiflora edulis f. edulis, basado en una matriz de similitud genética construida a partir del índice de Dice. 
útil para evaluar la diversidad genética a nivel intraespecífico, tal y como lo han evidenciado estudios realizados en cultivos de uchuva (7) y mora (8) en Colombia.

En términos generales con los marcadores RAM se evidenció una amplia diversidad genética (Figura 1), distribuida en las zonas en las que se cultiva la gulupa en el país. En el presente estudio no se encontró una concordancia con la procedencia de las muestras por departamento o localidad. Los genotipos que más variabilidad están aportando al grupo de genotipos estudiados son el 114 (Buenavista Cundinamarca) y el 39 (La Plata - Huila).

Estudios relacionados con la medición de la diversidad genética en poblaciones de Maracuyá ( $P$. edulis f. flavicarpa Deg) usando marcadores AFLP (9) y marcadores RAPD (10) en Brasil, muestran altos niveles de diversidad en esta especie, explicada por el hecho de que este país es centro de origen y diversidad del Maracuyá y porque los productores de esta fruta establecen los cultivos usando las semillas resultantes de sus propias plantaciones, de sus vecinos y de mercados de fruta sin tener en cuenta ninguna selección de características agromorfológicas (9).

Gang et al. (2004) (9) en un ensayo de marcadores AFLP en 36 accesiones de maracuyá amarillo en Brasil, encontraron una alta diversidad $(0,065$ - 0,496) entre las muestras analizadas, este estudio puede ser comparado con el estudio realizado con gulupa, teniendo en cuenta que son variedades pertenecientes a la misma especie.

Ocampo et al. (2007), Patiño (2002) y León (1987) (1113), reconocen al cultivo de gulupa como un cultivo relativamente nuevo en Colombia, e introducido desde Brasil alrededor del año 1950. El hecho que la gulupa sea una introducción de Brasil , le confiere un alto grado de diversidad, si se considera que el cultivo de gulupa es relativamente nuevo y establecido a partir de semillas, es probable que estas semillas hayan sido traídas de Brasil, provenientes de agricultores y/o del mercado de frutas, sin tener ningún control de la procedencia o de las características agromorfológicas, lo cual ha llevado a que los cultivos establecidos en Colombia sean diversos, ya que es un cultivo nuevo y aún no seleccionado según su potencial fenotípico y genotípico.

Es importante mencionar que la gulupa es una planta alógama, que presenta un sistema genético de autoincompatibilidad el cual favorece la polinización cruzada, por lo tanto el flujo de genes entre diferentes genotipos e inclusive entre diferentes especies del mismo género, genera altos índices de diversidad. Morillo et al. (2005), en su estudio en mora (Rubus spp.), argumenta que el polimorfismo genético, puede estar asociado con la naturaleza alógama de la especie, la cual tiende a favorecer la conservación de un alto porcentaje de heterocigotos, igualmente Bonilla et al. (2008), (7) atribuye la alta diversidad encontrada en su estudio y comparada con otras investigaciones, a la naturaleza alógama de la uchuva.

Los resultados presentados en este estudio se pueden asumir como una visión preliminar de la diversidad que presentan los cultivos de la gulupa en las principales zonas productoras de Colombia (Boyacá, Cundinamarca y Huila ), en donde se encontró una amplia diversidad genética, de la cual se podría disponer para futuros programas de mejoramiento genético (14).

Para desarrollar una estrategia de mejoramiento genético con miras a tener materiales seleccionados con características agromorfológicas o agronómicas de interés, es necesario ampliar el muestreo en cada uno de los departamentos e incluir el resto de departamentos productores, con el fin de evaluar la mayor diversidad posible, buscando características de importancia económica (rendimiento, resistencia/tolerancia a plagas y enfermedades, tamaño, grados Brix y peso).

\section{Conclusiones}

Los materiales de gulupa evaluados en este estudio mostraron una alta diversidad genética $(0,291-1)$, probablemente producto del método de propagación, de su procedencia diversa y el poco tiempo de establecimiento de los cultivos en el país.

La caracterización de la diversidad genética es un requerimiento necesario para el uso, conservación y mejoramiento de los recursos genéticos vegetales. De esta manera se propone el uso de la técnica de marcadores moleculares RAM como una alternativa practica, rápida, económica y efectiva para el estudio de la diversidad genética dentro de las poblaciones de P. edulis f. edulis.

\section{Agradecimientos}

A la Vicerrectoría Académica de la Universidad Javeriana por la financiación del trabajo, a los I.A William Escobar, Arnulfo Guzmán y Daniel Melo, a los productores Marcos Chavarro, Carlos Alirio Samboni, Faiber Ariza, Alexander Tribiño y Fernando Carvajal y a Gina Paola Solano por su apoyo en las colectas del material vegetal. 
Al Cepass y los productores de gulupa de Cundinamarca, Huila y Boyacá .

\section{Financiación}

Vicerrectoría Académica - Pontificia Universidad Javeriana

\section{Conflicto de intereses}

Los autores declaran que no existen conflictos de intereses

\section{Referencias}

1. Escobar L. Flora de Colombia. Passifloraceae. Tomo 10.Ed. Pinto y Lozano. Instituto de ciencias naturales. Museo de Historia Natural. Universidad nacional de Colombia. 1988. 51-88.

2. Hernández A, García N. Las passifloras. Libro rojo de las plantas de Colombia. 2006; V3. Pp 583-657. Bogotá, Colombia.

3. Hantula J, Dusabenyagasani M, Hamelin RC. Random amplified microsatellites (RAMS) - a novel method for characterizing genetic variation within fungi. European Journal for Pathogenens 1996; 26: 159-166

4. Muñoz JE, Morillo AC, Morillo Y. Uso de la técnica Microsatélites Amplificados al Azar (RAM) para estudios de diversidad genética en vegetales. Acta Agronómica 2008; 57(4): 219-226.

5. MCcouch SR, Kochert ZH, Wing ZY, Khush GS, Coffman WR, \& Tanksley SD. Molecular Mapping of Rice Chromosome. Theorical Applied Genetics 1988; 76: $815-829$.

6. Solano-Florez G, Márquez-Cardona MP, SchulerGarcía I. Optimización de la extracción de ADN de Passiflora ligularis para el análisis por medio de marcadores moleculares. Universitas Scientiarum 2009; 14 (1): 16-22.

7. Bonilla ML, Espinosa K, Posso AM, Vásquez HD, Muñoz JE. Caracterización molecular de 43 accesiones de uchuva de seis departamentos de Colombia. Acta Agronómica 2008; 57 (2): 109-115.

8. Cruz-Morillo A, Morillo Y, Muñoz JE, Vásquez HD, Zamorano A. Caracterización molecular con microsatélites aleatorios RAMs de la colección de mora, Rubus spp, de la Universidad Nacional de Colombia sede Palmira. Acta Agronómica 2005; 54 (2): 15-24.

9. Gang RMD, Ruggiero C, Lemos EGM, Grili GVG, Goncalves MM, Chagas EA \& Wickert E. Genetic Diversity In Yellow Passion Fruit Utilizing AFLP Molecular Markers. Revista Brasilera de Fruticultura 2004; 26 (3): 494-498.

10. Bellon G, Faleiro FG, Peixoto JR, Pereira K, Vilela NL, Carvhalo E, Braga GA MF, Texeira C. Variabilidade genética de acessos silvestres e comerciais de Passiflora edulis Sims con base em marcadores RAPD. Revista Brasileira de Fruticultura. 2007; 29 (1): 124127.

11. Ocampo J, Coppens G, Restrepo M, Jarvis A, Salazar M, Cetano C. Diversity of colombian Passifloraceae: biogeography and an updated list for conservation. Biota Colombiana 2007; 8 (1): 1-45.

12. Patiño VM. Historia y dispersión de los frutales nativos del neotrópico. CIAT. Cali, Colombia. 2002; p125.

13. León J. Botánica de los cultivos tropicales. Instituto Iberoamericano de Cooperación para la Agricultura. San José, Costa Rica. 1987; p95.

14. Bellon G, Faleiro FG, Peixoto JR, Pereira K, Vilela NL, Da Fonseca K, Braga MF. Variabilidade genética de acessos obtidos de populacoes cultivadas e silvestres de maracujazeiro-doce com base em marcadores RAPD. Revista Brasileira de Fruticultura 2009; 31 (1): 197-202. 